\title{
Dossî́
}

\section{O Ensino Religioso e a diversidade cultural: o sagrado na sala de aula}

Edile Maria Fracaro Rodrigues ${ }^{1}$

Resumo: Conviver com a diversidade é algo complexo e desafiador, talvez uma das grandes problemáticas da humanidade, principalmente quando se busca refletir o lugar do ser humano (seu propósito e significado de vida). O presente artigo, uma pesquisa bibliográfica, busca refletir sobre a "leitura religiosa" do cotidiano, sobre as expressões, os espaços e os gestos que remetem à dimensão do sagrado e, assim, à dimensão do outro. Como ver o diferente e aprender com ele a conviver em harmonia? Como abordar a questão da diversidade cultural e religiosa em sala de aula? A leitura do religioso pode favorecer uma leitura que vá além do cotidiano, dos acontecimentos, dos gestos, dos ritos, das normas e das formulações, para a compreensão da realidade de maneira profunda. Esse é o desafio que se apresenta a todos os docentes, mas especialmente aos docentes de Ensino Religioso. Assumir uma atitude que desenvolva a articulação com outras competências (disciplinas e conhecimentos) pode integrar os estudantes em um trabalho conjunto com vistas à educação integral. Portanto, cabe à educação utilizar-se da comunicação e do diálogo para promover o encontro com o outro e o seu Sagrado.

Palavras-chave: Educação. Ensino religioso. Diversidade cultural religiosa. Sagrado.

\section{Religious Education and cultural diversity: the sacred in the classroom}

Abstract: Living with diversity is complex and challenging, perhaps one of the great problems of humanity, especially when it seeks to reflect the place of the human being (purpose and meaning of life). This article seeks to reflect on the "religious Reading" of daily life, on the expressions, spaces and gestures that refer to the dimension of the Sacred and thus to the dimension of the other. How to see the different and learn, with this one, to live in harmony? How to approach the issue of cultural and religious diversity in the classroom? The reading of the religious favors a reading that goes beyond the surface of things, events, gestures, rites, norms and formulations, to the understanding of reality in a profound way. This is the challenge facing all teachers, but especially teachers of Religious Education. Taking an attitude that develops the articulation with other competences (disciplines and knowledge), can integrate the students in a 
joint work with a view to the holistic education. It is therefore up to education to use communication and dialogue to promote the encounter with the other and his Sacred. Keywords: Education. Religious education. Cultural diversity and religion. Sacred.

\section{Educación y derechos humanos: educando para la concientización, para la in- clusión y para la humanización}

Resumen: Vivir la diversidad es algo complejo y desafiante, quizás una de las grandes problemáticas de la humanidad, en particular cuando se busca reflejar el lugar del ser humano (su propósito y significado de vida). El presente artículo, una investigación bibliográfica, busca reflexionar sobre la "lectura religiosa" de lo cotidiano, sobre las expresiones, los espacios y los gestos que remiten a la dimensión de lo Sagrado y, así, a la dimensión del otro. ¿Cómo ver lo diferente y aprender, con él, a convivir en armonía? ¿Cómo abordar la cuestión de la diversidad cultural y religiosa en la clase? La lectura de lo religioso puede favorecer una interpretación que vaya más allá de la superficie de las cosas, acontecimientos, gestos, ritos, normas y formulaciones, para la comprensión de la realidad de manera profunda. Este es el desafío que se presenta a todos los docentes, pero especialmente a los docentes de Educación Religiosa. Asumir una actitud que desarrolle la articulación con otras competencias (disciplinas y conocimientos), puede integrar a los estudiantes en un trabajo conjunto con vistas a la formación integral. Por lo tanto, corresponde a la educación utilizar la comunicación y el diálogo para promover el encuentro con el otro y su Sagrado.

Palabras clave: Educación. Enseñanza religiosa. Pluralidad cultural religiosa. Sagrado.

\section{Introdução}

A compreensão do ser humano, que busca respostas para a sua existência em diferentes formas de crer ou a opção de não crença, levanta possibilidades para investigar a maneira de pensar e o modo de agir que podem orientar e, até mesmo, condicionar e determinar a concepção de mundo, a compreensão da vida e a noção de transcendência do ser humano. Por isso, para compreender uma sociedade, é necessário entender as influências de inúmeras organizações, inclusive as religiosas, para uma completa caracterização social.

A questão da diversidade religiosa, uma realidade cada vez mais percebida, é um fenômeno universal que ocorre em diversas realidades e aspectos culturais. Os direitos fundamentais de liberdade e de expressão religiosa são frutos de uma sociedade pluralista que se expressa no Estado não confessional e laico. A laicidade não é a negação da fé, mas protege as confissões minoritárias de discriminação e, de forma democrática, possibilita a relação entre o cidadão e o Estado, o privado e o público.

E a reflexão sobre a diversidade cultural e religiosa e os diferentes sentidos derivantes dessa diversidade é importante para compreender a sociedade a partir de uma leitura da dinâmica sociorreligiosa. Como ver o diferente e 
aprender com ele a conviver em harmonia? Como abordar a questão da diversidade cultural e religiosa em sala de aula? Surgem então os desafios para o Ensino Religioso.

Pensar o Ensino Religioso a partir do espaço escolar é pensar na instituição educacional que está contextualizada em cenários históricos-sociais que configuram manifestações das mais diferentes formas e que interferem nas relações família-escola, professor-aluno, sociedade-conhecimento e outras derivações (RODRIGUES; JUNQUEIRA; MARTINS FILHO, 2015, p. 14).

O documento da área de Ciências da Religião e Teologia da CAPES (2016) reconhece a modalidade de Ensino Religioso em uma abordagem não confessional. Segundo Senra (2017, p. 10):

A área de Ciências da Religião e Teologia se une aos esforços de todos os pesquisadores, pesquisadoras e pessoal docente que, vinculados à pós-graduação, à graduação e à educação básica, contribuem para superar toda forma de proselitismo religioso nas escolas públicas - lugar em que a questão do Ensino Religioso é um tema bastante sensível.

A compreensão do Ensino Religioso a partir do conhecimento religioso, conforme estabelecido pela Base Nacional Comum Curricular (BNCC), então, precisa ocorrer a partir da organização da educação e da relação da religião na sociedade. "O Ensino Religioso busca construir, por meio do estudo dos conhecimentos religiosos e das filosofias de vida, atitudes de reconhecimento e respeito às alteridades" (BRASIL, 2017, p. 437).

Sendo assim, para valorizar a diversidade cultural presente na sociedade brasileira, além dos novos desafios e olhares para a complexidade do Ensino Religioso como componente curricular, são requeridas práticas que valorizem a expressão dessa diversidade em sala de aula.

O presente artigo, uma pesquisa bibliográfica, busca refletir sobre a "leitura religiosa" do cotidiano, as expressões, os espaços e os gestos que remetem à dimensão do sagrado e, assim, à dimensão do outro, pois a religiosidade é vivida em contextos culturais e individuais, que influenciam a vida em sociedade, a história e até a economia.

\section{Diversidade cultural e religiosa}

A cultura é uma totalidade complexa, feita de normas, hábitos, repertórios de ação e representação, adquirida pelo ser humano enquanto partícipe de uma sociedade. Para a compreensão de uma sociedade, segundo Benedict (2013, p. 
42), é preciso entender as "principais motivações emocionais e intelectuais dessa sociedade". Para a autora, "as culturas são mais do que a soma dos traços que as compõem", pois, apesar de saber tudo sobre determinado processo, pode-se não compreender nada do contexto em que esse processo está inserido.

Assim, ao longo do tempo, as civilizações buscaram estabelecer sua identidade por meio de um conjunto de valores e comportamentos que as diferenciasse das demais, tanto no patrimônio material, expressando-se nas vestimentas, nas obras de arte, na arquitetura, quanto no patrimônio imaterial, por meio da culinária, da religião, das lendas e dos mitos, do artesanato e da conduta individual do indivíduo em sociedade. Essa materialização forma o patrimônio de uma comunidade e, efetivamente, é o conjunto de bens que uma pessoa ou uma entidade possui. Ou seja, tudo aquilo que constitui um bem apropriado pelo ser humano, com suas características únicas e particulares, pode ser considerado patrimônio de uma comunidade.

Segundo Lévy (1990, p. 20):

É impossível separar o humano de seu ambiente material, assim como dos signos e das imagens por meio dos quais ele atribui sentido à vida e ao mundo. Da mesma forma, não podemos separar o mundo material — e menos ainda sua parte artificial — das ideias por meio das quais os objetos técnicos são concebidos e utilizados, nem dos humanos que os inventam, produzem e utilizam. [...] mesmo supondo que realmente existam três entidades - técnica, cultura e sociedade - em vez de enfatizar o impacto das tecnologias, poderíamos igualmente pensar que as tecnologias são produtos de uma sociedade e de uma cultura. Mas a distinção traçada entre cultura (a dinâmica das representações), sociedade (as pessoas, seus laços, suas trocas, suas relações de força) e técnica (artefatos eficazes) só pode ser conceitual.

O dinamismo da cultura considera que o comportamento coletivo é também o comportamento de indivíduos. Para Benedict (2013, p. 171), "na realidade, a sociedade e o indivíduo não são antagonistas. A cultura fornece a matéria-prima com a qual o indivíduo faz a sua vida".

A ideia de posse coletiva como parte do exercício da cidadania inspirou a utilização do termo "patrimônio" para designar o conjunto de bens de valor cultural que passaram a ser propriedade da nação, ou seja, do conjunto de todos os cidadãos.

O patrimônio cultural como um todo abrange uma infinidade de bens objetos, artefatos, inscrições, culinária, danças, obras de arte, documentos, monumentos, edificações, teatros, museus, entre muitos outros, e cada um deles receberá um acréscimo de outros valores, como histórico, artístico, etnográfico, arqueológico ou paisagístico - de acordo com as suas características individuais. 
Sua função primordial era de reforçar a noção de cidadania e instruir a nação. Assim, os monumentos seriam a materialização da identidade nacional francesa. As imagens materializadas em objetos, construções e representações são o resultado da cultura inserida no contexto de determinada sociedade, compõem elementos de identidade e fornecem para o indivíduo uma visão de mundo, valores morais e estilo de vida, o que irá diferenciá-lo dos demais.

As culturas são produzidas pelos grupos sociais ao longo das suas histórias, na construção de suas formas de subsistência, na organização da vida social e política, nas suas relações com o meio e outros grupos, na produção de conhecimentos, entre outros fatores. A diferença entre culturas é fruto da singularidade desses processos em cada grupo social. A partir da busca da compreensão de si mesmo e do mundo, em relação aos fatos desconhecidos, o ser humano, nos mais diversos cantos do planeta, estruturou a religião e, assim, indicou significados ao seu caminhar (RODRIGUES; JUNQUEIRA; MARTINS FILHO, 2015).

Em relação à religião, considerar o aspecto instintivo do ser humano para com a religião é considerar as manifestações observadas por meio dos tempos, em todas as diversas culturas. E como uma das atividades que possibilita ao ser humano conhecer-se, construir e significar suas experiências, a religiosidade enquanto experiência é objeto de investigação científica, pois a experiência humana pode ser investigada (BENKÖ, 1981).

A visão de mundo do ser humano no início de sua história era uma visão orgânica, que compreendia quase que exclusivamente a interdependência entre os fenômenos materiais e transcendentais. A descoberta da transcendência garante a continuidade da vida, e o medo da morte é solucionado pelos ritos, pela magia, pelos mitos (TRENTI, 1999). Nesse contexto, o conhecimento, então, poderia ser entendido como entrelaçamento de razão e fé, e o transcendente era o centro da organização social. Posteriormente, a leitura do mundo passou a ser antropocêntrica, colocando o ser humano em uma nova perspectiva.

Ao contemplar a linha do tempo da história da humanidade, compreendem-se e identificam-se os diferentes fatos religiosos que se manifestam no desenvolvimento do ser humano. O desenho (símbolo), por exemplo, tinha um caráter de mistério, que se caracterizava pelos gestos que demonstravam a tentativa de dominar o inexplicável e buscar uma intervenção milagrosa. Dessa forma, a pintura de figuras de animais nas cavernas não era apenas expressão artística.

Como fenômeno universal, a diversidade religiosa traz a combinação de práticas religiosas provenientes das diferentes religiões, buscando formas não institucionais de vivenciar as questões profundas do ser. A religiosidade é vivida em contextos sociais e individuais, e cada religião busca oferecer orientação que dê sentido a tudo que cerca o ser humano. Favorecer, pois, diferentes leituras e experiências, especialmente em uma cultura com base em presenças, realidades e conceitos, é considerar todo signo visual ou sonoro para perceber o potencial 
informativo enquanto faz referência a um objeto. Acrescentar à comunicação oral e escrita a imensa riqueza de uma comunicação por meio de imagens e sons é significativo para a presente geração.

\section{A sala de aula: o encontro dos diversos mediado pelo conhecimento}

Na primeira década do terceiro milênio, Edgar Morin (2000) sistematizou um conjunto de reflexões que serve como ponto de partida para repensar a educação do século XXI. As reflexões de Morin trazem inquietações para a educação e a formação docente, pois, ao se falar da educação do futuro, faz-se necessário refletir sobre competências e habilidades necessárias para tal momento, bem como os desafios, as oportunidades e os dilemas que tais mudanças trazem no seu bojo.

$\mathrm{Na}$ educação do futuro, para Morin (2000, p. 55), deve ser levada em conta a complexidade humana.

A complexidade humana não poderia ser compreendida dissociada dos elementos que a constituem: todo desenvolvimento verdadeiramente humano significa o desenvolvimento conjunto das autonomias individuais, das participações comunitárias e do sentimento de pertencer à espécie humana.

Para o autor, o humano é compreendido a partir da unidade na diversidade e da diversidade na unidade, pois há uma unidade no múltiplo e uma multiplicidade no que é uno. Nas palavras de Morin (2000, p. 94-95), é preciso ir além da compreensão intelectual desse humano, pois "compreender inclui, necessariamente, um processo de empatia, de identificação e de projeção. Sempre intersubjetiva, a compreensão pede abertura, simpatia e generosidade".

E qual seria, então, a pauta de uma educação para o futuro? Sacristán (2015, p. 12) afirma que:

Inevitavelmente, educamos para o futuro, mas não para "um" futuro determinado, que vá muito além do tempo de nossas vidas e das de nossos filhos. Refletirmos sobre como deveria ser o porvir é uma forma de projetar nossa visão de mundo desejável. As ações que podemos empreender para consegui-lo não podem alcançar o tempo distante que virá, mas somente o tempo de nossas vivências. $\mathrm{O}$ tempo futuro diante de nós corresponderá àqueles que tenham de vivê-lo como presente, e esses o abordarão com a bagagem que lhes tenham dado.

A educação escolar pode ser entendida como ciência prática que tem o processo de ensino e aprendizagem como objeto de investigação de um fenômeno. E nesse processo a interação consigo e com o outro é mediada pelo conhecimento. Na concepção de educação de Tardif (2002, p. 151) está a: 
ação que o ser humano exerce voluntária e conscientemente sobre si mesmo ou sobre outro ser humano a fim de se formar ou de formá-lo em função de certas representações de sua própria ação e da natureza, dos modos e das consequências dessa ação.

Pensando em uma formação integral, proposta pela BNCC (BRASIL, 2017, p. 59), vê-se que o compromisso da escola é:

\begin{abstract}
Propiciar uma formação integral, balizada pelos direitos humanos e princípios democráticos, é preciso considerar a necessidade de desnaturalizar qualquer forma de violência nas sociedades contemporâneas, incluindo a violência simbólica de grupos sociais que impõem normas, valores e conhecimentos tidos como universais e que não estabelecem diálogo entre as diferentes culturas presentes na comunidade
\end{abstract}

A educação integral envolve o desenvolvimento harmonioso de todos os canais de relação do ser humano com o mundo, pois não tem como objetivo apenas capacitar o indivíduo para entender o funcionamento do mundo, mas também enfrentar os desafios presentes no cotidiano do existir humano.

Em meio a conteúdos formais, o espaço escolar pode ser um espaço de superação de preconceito e de um processo de ensino e aprendizagem homogeneizado. A diversidade humana está posta desde os primórdios da humanidade, mas somente a partir do final do século XX é que a sociedade se deu conta dessa especificidade. Como espaço de desenvolvimento de um sistema de ensino interconectado com os problemas da sociedade atual, desenvolve, ou deveria desenvolver, a valorização de diferentes grupos sociais, políticos, econômicos, étnicos e religiosos, possibilitando a reflexão de questões que contemplem as diferenças, ou seja, a diversidade na e da sociedade que compõe o espaço escolar.

Como local da aprendizagem, o espaço escolar pode trabalhar as regras e as normas do espaço público democrático, buscando a superação de todo e qualquer tipo de discriminação e exclusão social, valorizando cada indivíduo e todos os grupos que compõem a sociedade brasileira, garantindo o exercício da cidadania, o direito da expressão religiosa e o diálogo intercultural e inter-religioso.

A religiosidade é uma das atividades em que o ser humano pode se conhecer, construir, interpretar suas experiências e encontrar um sentido à própria existência. No centro dessa discussão está o Ensino Religioso e, com isso, a religião no espaço escolar como um tipo de conhecimento humano, "que responde às questões existenciais do ser humano e reflete sobre a sua dimensão religiosa. É o mesmo ser humano que pensa, sente e vive a experiência religiosa" (JUNQUEIRA et al., 2017, p. 21). 
Uma profunda reflexão vem sendo desencadeada em relação à formação do professor de Ensino Religioso.

\begin{abstract}
Pensar a formação do docente do Ensino Religioso é uma maneira de contribuir para que ele possa, nos diferentes contextos brasileiros, se constituir, de fato, como profissional, possuindo os mesmos direitos dos outros professores e tendo mais autonomia para participar da construção de um projeto educativo, na perspectiva do fenômeno religioso, como construção sociocultural, veiculadora de valores éticos e da dimensão da religiosidade (CAETANO, 2007, p. 19).
\end{abstract}

O que se deve, portanto, considerar em qualquer área do conhecimento é a intenção da prática pedagógica, bem como as políticas públicas que gerem o sistema educacional. $\mathrm{O}$ conhecimento religioso faz parte da dimensão humana e vai além da superfície dos fatos, dos acontecimentos, dos gestos, dos ritos, das normas e das formulações. Essa percepção pode auxiliar o ser humano a interagir na sociedade de forma responsável e atuante, desenvolvendo os laços de solidariedade e tolerância recíproca, tal como disposto pelo artigo $32 \mathrm{da} \mathrm{LDB} \mathrm{no} 9.394$ (BRASIL, 1996).

A abordagem pedagógica do conhecimento religioso exige o entendimento e a reflexão do espaço escolar. Na BNCC, são estabelecidas as competências e as habilidades do Ensino Religioso, bem como o seu objeto de estudo, que é o conhecimento religioso.

Todos os períodos históricos brasileiros mantiveram a regulamentação do Ensino Religioso, segundo a visão da época, o que contribuiu para que esse componente curricular passasse por diferentes formas de viabilização e de expressão.

Assim, a compreensão do Ensino Religioso a partir do objeto de estudo proposto pela BNCC, o conhecimento religioso, precisa ocorrer a partir da organização da educação escolar e da relação da religião na sociedade e da valorização da diversidade cultural e religiosa presente na sociedade brasileira.

O estabelecido pela BNCC (BRASIL, 2017, p. 434) sobre o conhecimento religioso é que:

O conhecimento religioso, objeto da área de Ensino Religioso, é produzido no âmbito das diferentes áreas do conhecimento científico das Ciências Humanas e Sociais, notadamente da(s) Ciência(s) da(s) Religião(ões). Essas Ciências investigam a manifestação dos fenômenos religiosos em diferentes culturas e sociedades enquanto um dos bens simbólicos resultantes da busca humana por respostas aos enigmas do mundo, da vida e da morte. De modo singular, complexo e diverso, esses fenômenos alicerçaram distintos sentidos e significados de vida e diversas ideias de divindade(s), em torno dos quais se organizaram cosmovisões, linguagens, saberes, crenças, mitologias, narrativas, textos, símbolos, ritos, doutrinas, tradições, movimentos, práticas e princípios éticos e morais. Os fenômenos religiosos em suas múltiplas ma- 
nifestações são parte integrante do substrato cultural da humanidade. Cabe ao Ensino Religioso tratar os conhecimentos religiosos a partir de pressupostos éticos e científicos, sem privilégio de nenhuma crença ou convicção. Isso implica abordar esses conhecimentos com base nas diversas culturas e tradições religiosas, sem desconsiderar a existência de filosofias seculares de vida.

Vê-se no texto da BNCC a expressão "conhecimentos religiosos”, o que supõe o convívio interdisciplinar não só das diferentes áreas do conhecimento, mas dos conhecimentos dentro da própria área do Ensino Religioso, e reforça-se que "os fenômenos religiosos em suas múltiplas manifestações são parte integrante do substrato cultural da humanidade".

Passos (2011, p. 69) afirma que, ao reconhecer a existência do conhecimento religioso, parte-se de sua legitimidade antropológica e política, além de um discurso de natureza epistemológica que pressupõe:

a) uma abordagem singular da experiência religiosa, como dado que mostra uma constante, para além das diversidades de experiências de cada tradição religiosa em específico; b) um discurso que afirma a autenticidade da religião, como fenômeno que oferece uma visão e um posicionamento para os sujeitos religiosos; c) a afirmação de uma função legítima para a religião no conjunto maior da vida individual e social; d) a descrição de vivências religiosas a partir dos processos que as constituem como interiorização e exteriorização de determinados conteúdos; e) a possibilidade de sistematização das representações e práticas religiosas, do ponto de vista conceitual; f) a afirmação de um modo simbólico de ver e comunicar a realidade, distinto de outras formas de ver e descrever a realidade verificáveis empiricamente.

Para o autor, não há distância ou oposição entre o conhecimento religioso e o conhecimento racional e afirma que o conhecimento religioso é "composto como negociação complexa entre indivíduos e disposto em uma temporalidade capaz de amadurecer e produzir consensos" (PASSOS, 2011, p. 79), compondo uma visão de realidade.

O olhar do conhecimento religioso pode contribuir para a superação de uma realidade segmentada, "pois faz parte da vida humana e mostra-se como um dado desde que que nossa consciência emergiu como distintivo da espécie homo na longa escalada da hominização” (PASSOS, 2011, p. 70).

O Brasil, rico em sua diversidade de origem, construída por várias etnias, culturas e religiões, permite a convivência de uma diversidade de manifestações. "Enquanto patrimônio da humanidade, o conhecimento religioso pode proporcionar ao estudante do ER [Ensino Religioso] oportunidades de aprendizagem que compreendam os movimentos específicos das diversas culturas [...]" (RODRIGUES; JUNQUEIRA; MARTINS FILHO, 2015, p. 97). 
Entende-se aqui que os autores não se referem ao conhecimento religioso dogmático e infalível, mas a partir da compreensão dos objetivos para o Ensino Religioso estabelecidos pela BNCC (BRASIL, 2017, p. 436), que torna aplicável tal conhecimento em sala de aula:
a) Proporcionar a aprendizagem dos conhecimentos religiosos, culturais e estéticos, a partir das manifestações religiosas percebi- das na realidade dos educandos;
b) Propiciar conhecimentos sobre o direito à liberdade de consci- ência e de crença, no constante propósito de promoção dos direi- tos humanos;
c) Desenvolver competências e habilidades que contribuam para o diálogo entre perspectivas religiosas e seculares de vida, exercitan- do o respeito à liberdade de concepções e o pluralismo de ideias, de acordo com a Constituição Federal;
d) Contribuir para que os educandos construam seus sentidos pes- soais de vida a partir de valores, princípios éticos e da cidadania.

Com a compreensão dos modos de organização das várias sociedades, depreende-se a constituição de conhecimentos religiosos e sua contextualização espacial e temporal. No espaço escolar, a formação do indivíduo, enquanto cidadão, ultrapassa as expectativas do professor, de maneira que o aluno assuma suas atitudes cotidianas, que vão além dos direitos e deveres, em prol dos interesses sociais, desenvolvendo o respeito ao outro.

O Ensino Religioso também possibilita a ampliação dos recursos didáticos com base em abordagens artísticas das expressões religiosas, como música, dança, comida, pintura, escultura, teatro, literatura, cinema, fotografia e arte digital. Também é possível refletir "sobre os princípios religiosos e as questões sobre as quais se debruçam os direitos humanos, como as relações étnicas, de gênero, das mulheres, das crianças, dos idosos e da vida no campo, dentre outras" (KLUCK, 2017, p. 142).

Existem ainda outros desafios a serem superados. Para criar, planejar, realizar, gerir e avaliar situações didáticas eficazes para a aprendizagem e o desenvolvimento dos estudantes, é preciso que o professor compreenda, com razoável profundidade e com a necessária adequação à situação escolar, os conteúdos das áreas do conhecimento que serão objeto de sua atuação didática, os contextos em que se inscrevem e as temáticas transversais ao currículo.

Para Costella (2004, p. 97), é preciso distinguir o objeto de estudo em cada espaço em que é compreendido. Dessa forma, o que é objeto de fé para as igrejas, é objeto de estudo para o espaço escolar.

Isto supõe a distinção entre fé/crença e religião, entre o ato subjetivo de crer e o fato objetivo que o expressa. Essa condição implica a superação da identificação entre religião e igreja, salientando sua função social e o seu potencial de humanização das culturas. 
E no espaço escolar, ao mediar o processo de construção e significação dos saberes, o professor deve balizar sua prática pelo diálogo e pelo debate por meio do respeito às diversidades.

As competências específicas de Ensino Religioso para o Ensino Fundamental estabelecidas pela BNCC são as seguintes:

1. Conhecer os aspectos estruturantes das diferentes tradições/ movimentos religiosos e filosofias de vida, a partir de pressupostos científicos, filosóficos, estéticos e éticos.

2. Compreender, valorizar e respeitar as manifestações religiosas e filosofias de vida, suas experiências e saberes, em diferentes tempos, espaços e territórios.

3. Reconhecer e cuidar de si, do outro, da coletividade e da natureza, enquanto expressão de valor da vida.

4. Conviver com a diversidade de crenças, pensamentos, convicções, modos de ser e viver.

5. Analisar as relações entre as tradições religiosas e os campos da cultura, da política, da economia, da saúde, da ciência, da tecnologia e do meio ambiente.

6. Debater, problematizar e posicionar-se frente aos discursos e práticas de intolerância, discriminação e violência de cunho religioso, de modo a assegurar os direitos humanos no constante exercício da cidadania e da cultura de paz (BRASIL, 2017, p. 437).

Na relação entre competências e conhecimentos, há que se considerar que a constituição da maioria das competências objetivadas na Educação Básica atravessa as tradicionais fronteiras disciplinares e exige um trabalho integrado entre professores de diferentes disciplinas ou áreas afins. Decorre daí a necessidade de repensar a perspectiva metodológica, propiciando situações de aprendizagem focalizadas em situações-problema ou no desenvolvimento de projetos que possibilitem a interação dos diferentes conhecimentos, que podem estar organizados em áreas ou disciplinas, conforme o desenho curricular da escola. Situações escolares de ensino e aprendizagem são comunicativas, nas quais professores e alunos coparticipam, concorrendo com influência igualmente decisiva para o êxito do processo.

Pode-se afirmar, com grande margem de certeza, que o estudante aprende melhor quando se torna protagonista, tomando parte de forma direta na construção do conhecimento que adquire, e quando as propostas de ensino estão integradas levando em consideração as experiências vividas, relacionadas à realidade de forma que não se apresentem como matérias de um currículo estanque. Pressupõe-se, assim, que o conhecimento religioso, articulado às experiências vividas pelos estudantes, pode se constituir em um conhecimento pertinente para além da compreensão do processo histórico da humanidade. 
Em relação ao desenvolvimento das seis competências do Ensino Religioso, vê-se claramente a importância do diálogo com outros conhecimentos (científico, filosófico, estético e ético), e o professor pode valer-se das práticas de linguagem e da experiência estética e intercultural dos estudantes.

Necessita-se, assim, valorizar todo o conhecimento que os diferentes grupos trazem para a sala de aula, enriquecendo muito mais o ensino e a aprendizagem, para o desenvolvimento de cidadãos com postura crítica diante dos problemas sociais e engajamento na sua resolução.

\section{O sagrado como construção de sentido}

Tendo como baliza que, no processo educacional, habitualmente, o que se faz é uma análise do produto e da resposta. Rodrigues, Junqueira e Martins Filho (2015, p. 115) apontam que o conhecimento não é somente resultado, não é somente produto, não é somente resposta, mas o processo da construção do conhecimento também deve ser considerado.

Para os autores, há uma articulação intrínseca entre as áreas de conhecimento, pois elas fazem referência "às noções e [aos] conceitos essenciais sobre fenômenos, processos, sistemas e operações, que contribuem para a constituição de saberes, conhecimentos, valores e práticas sociais indispensáveis ao exercício de uma vida de cidadania plena" (RODRIGUES; JUNQUEIRA; MARTINS FILHO, 2015, p. 115). A leitura e a interpretação da realidade possibilitam a participação do cidadão na sociedade de forma autônoma.

O sagrado enquanto experiência traz elementos, como imagens, símbolos, gestos e espaços, que possibilitam sua leitura. Favorecer a partilha dessa experiência é fomentar o diálogo inter-religioso e a tolerância a toda crença, contribuindo, assim, para a formação de cidadãos abertos para a diversidade cultural e religiosa.

A dimensão do sagrado, se compreendida a partir do processo histórico da humanidade, permite a reflexão e a proposição do Ensino Religioso não como ensino de uma religião ou das religiões na escola, mas sim uma disciplina centrada na antropologia religiosa. Desde o período pré-histórico, por meio da reconstrução dos sons ouvidos na natureza até as demonstrações artísticas, passando pelas noções de organização urbana presente nas construções civis e na escultura, o ser humano foi aprendendo a partir desse cotidiano. Para Rodrigues (2017, p. 207), esse cotidiano está permeado "de situações que envolvem desafios cognitivos, sociais e emocionais. Frente a esses desafios, são mobilizados saberes que decorrem da aprendizagem, um processo significativo e complexo que envolve o indivíduo na sua totalidade". E ainda aponta que:

A experiência religiosa está, inicialmente, relacionada às experiências religiosas da família, mas a qualidade das relações comunitárias, seja na família ou em outros grupos sociais, proporciona o 
equilíbrio entre os interesses individuais e os coletivos. Assim, a vivência comunitária, muito mais do que promove normas e leis, estimula o sentimento de pertença. E a fé pode trazer esse sentimento de pertença (RODRIGUES, 2017, p. 208).

As diferentes linguagens são elementos que, desde os primórdios, organizaram culturas e sociedades, repassando e evoluindo conceitos em prol da valorização do ser humano.

Mesmo que a civilização humana tenha sido estruturada a partir da escrita, é importante desenvolver um olhar para uma linguagem que permeia outras formas de comunicação, a partir de conceitos básicos, como percepção, interpretação, sensibilidade e todos os sentidos. Se não houvesse uma cultura em comum, representada por meio de uma língua ou um código de conduta, ficaria difícil criar uma identidade entre diversos indivíduos, e qualquer tentativa de criação de leis, da moral e dos costumes esbarraria nas particularidades de cada um e, por consequência, ninguém saberia como se portar em determinada sociedade.

As diferentes manifestações presentes na dimensão religiosa/espiritual são abordadas visando ao entendimento da diversidade religiosa e de sua complexa composição. Nessa composição, encontram-se os valores éticos e morais que pautam a vida da pessoa, inclusive trazendo a percepção do que lhe é sagrado.

A reflexão sobre a presença de uma combinação harmoniosa de práticas religiosas provenientes das diferentes religiões e das filosofias de vida, que estão ancoradas em princípios cujas fontes não advêm do universo religioso, é uma maneira de firmar a identidade religiosa do estudante e as marcas de sua cultura. A renúncia dessas marcas pode levar a uma desvalorização das novas culturas que lhe forem apresentadas. "Se as marcas culturais são bem tratadas, mas não as absolutizas, então se é marcado pela nova cultura" (FREIRE; FAUNDEZ, 1985, p. 17).

Para Sérvio (2014, p. 2001), "discutir as imagens que nos cercam é algo fundamental para a Cultura Visual”. Sérvio (2014, p. 198) aponta que a cultura visual está ligada "à visualidade, ou seja, à dimensão cultural do olhar, dimensão histórica e contextual". Assim, vivências e pontos de vista podem afetar a construção de um objeto de pesquisa, por isso a permanente crítica é necessária para que a visão e a interpretação dos dados e fatos não sejam únicas e tampouco uma sentença final.

As imagens materializadas em objetos, espaços e representações são o resultado da cultura inserida no contexto de determinada sociedade, são elementos de identidade que fornecem para o indivíduo uma visão de mundo, seus valores morais e o estilo de vida que irá diferenciá-lo dos demais, na busca de um mundo que luta e se conscientiza cada vez mais pela vivência da diversidade.

Bonafé (2015, p. 111) aponta que: 
A escola do futuro deverá se reencontrar com uma leitura crítica da cidade; não a cidade como excursão escolar, ou seja, como saída pontual, estudo ou exploração, para voltar às quatro paredes da sala de aula, onde o currículo ficou encerrado e imóvel. [...] é a reivindicação de um novo modelo escolar que há de contemplar, necessariamente, a experiência da cidade como prática de significação e subjetivação, selecionando e ordenando formas de conhecer cruzadas por relações de poder.

O autor reitera (2005, p. 11): "a cidade produz saberes nos quais se mostram as tensões e os conflitos por darem significado às experiências da vida". Para Bonafé (2015, p. 111), pelas ruas da cidade "circulam modos de comportamento, valores cívicos e morais, estilos e modos de vida, práticas culturais elaboradas, em relação aos quais construímos significados sobre o sentido de ser cidadão".

Gil Filho (2008, p. 145) aponta que a "espacialidade das expressões religiosas é a dimensão onde o espaço sagrado se apresenta na sua dinâmica imediata, é o contexto das práticas religiosas no cotidiano". O autor argumenta "que a religião se apresenta como uma estrutura estruturante e por esta premissa relaciona-se dialeticamente com as estruturas estruturadas de determinada realidade cultural e religiosa" (GIL FILHO, 2008, p. 144).

A leitura dos espaços é a leitura da cidade, do ambiente em que o estudante está inserido. E a leitura do espaço sagrado não pode se limitar apenas a aspectos da religiosidade, mas também da cidadania.

Nesse contexto, então, é proposto o exercício de não apenas ler o religioso, mas educar para "saber olhar" o ser humano em sua diversidade de manifestações. A partir desse processo, pretende-se que o estudante aprenda a observar para saber a identificação do objeto/função/significado, visando ao desenvolvimento da percepção visual e simbólica.

Ao solicitar aos estudantes olhar de novo para seu cotidiano, suas expressões, seus espaços e seus gestos que remetem à dimensão do sagrado, é uma estratégia para compreender e respeitar a diversidade cultural e religiosa.

Ter como base a comunicação, as reflexões, as ações, as observações, as impressões, os sentimentos e a fé pode levar a elementos que estruturem uma ação pedagógica voltada para o diálogo e a interculturalidade. A reflexão pedagógica sobre um ser humano dotado de razão, afetividade, inteligência e religiosidade possibilita a criação de um espaço educativo aberto para o diverso, pois cada ser humano é único na sua diversidade.

\section{O sagrado do outro}

A LDB no 9.394/96, em seu artigo 32, valoriza o pleno domínio da leitura, da escrita e do cálculo, assim como a compreensão do ambiente natural e social, 
do sistema político, da tecnologia, das artes e dos valores em que se fundamenta a sociedade e do desenvolvimento da capacidade de aprendizagem, de aquisição de conhecimentos e de habilidades, além da formação de atitudes e valores. Não menos importante, a LDB também valoriza o fortalecimento dos vínculos familiares, dos laços de solidariedade e de respeito à diversidade cultural e religiosa em que se assenta a vida social (BRASIL, 2006).

O que se requer para que realmente a educação no país avance é uma prática reflexiva que pode ser desenvolvida a partir da conscientização de que é necessário um olhar crítico para si e para todos os envolvidos na construção do conhecimento, em todos os níveis de formação propostos pela LDB n 9.394/96.

É sob o fundamento da ética da alteridade que a aprendizagem com o outro precisa ser compreendida. A Organização das Nações Unidas para a Educação, a Ciência e a Cultura (UNESCO) e a Associação Palas Athena produziram o livro "Cultura de paz: da reflexão à ação; balanço da década internacional da promoção da cultura de paz e não violência em benefício das crianças do mundo" (2010). No prefácio de Vincent Defourny, representante da UNESCO no Brasil, lê-se: "A tolerância e o diálogo cultural e inter-religioso constituem, assim, facetas marcantes deste 'novo humanismo' calcado de maneira evidente na ideia de cultura de paz” (UNESCO; ASSOCIAÇÃO PALAS ATHENA, 2010, p. 8).

Ao fazer uma retrospectiva das ações da UNESCO, Noleto (2010, p. 13) aponta que uma educação voltada para a cultura de paz "inclui a promoção da compreensão, da tolerância, da solidariedade e do respeito às identidades nacionais, raciais, religiosas, por gênero e geração, entre outras, enfatizando a importância da diversidade cultural". Noleto (2010) ainda afirma que é possível pensar em uma educação que efetivamente contribua para a construção de uma cultura de paz.

O encontro com o outro pode trazer conflitos, mas conflito não é confronto. Jares (2008) aponta que conflito e convivência são duas realidades sociais inerentes a toda forma de vida em sociedade. Para o autor (2008), a convivência é marcada por polos estabelecidos a partir de códigos valorativos, que são subjetivos, no marco de determinado contexto social. Entretanto, apesar de a convivência ser potencialmente cruzada por relações de conflito, isso de modo algum significa ameaça à convivência. Jares (2008) aponta seis marcos que incidem na convivência, ou ao menos aqueles que ele considera mais importantes:

- A família - espaço inicial de socialização e no qual aprendemos os primeiros hábitos de convivência.

- O sistema educacional - como artífice cultural, a escola gera ritos que marcam a convivência. 
- O grupo de iguais - tradicionalmente, a incidência dessa variável situava-se a partir da adolescência, mas sua ocorrência vem baixando para idades mais precoces, por conta dos tipos de relação social que se vive.

- Os meios de comunicação - com forte incidência nos modelos de convivência, a televisão e a internet.

- Espaços e instrumentos de lazer - boa parte desses espaços transmite práticas e valores consumistas, violentos e até discriminatórios. Meninos, meninas e adolescentes reafirmam seus valores e modelos de convivência na interação e nas escolhas que estabelecem com os espaços e os instrumentos de lazer.

- Contextos político, econômico e cultural dominante - "todos os âmbitos anteriores se dão e interagem, no micro ou no mais global dos planos médio e macro, em um determinado contexto político, econômico, social e cultural" (JARES, 2008, p. 50-51).

A convivência nesses seis marcos é um contínuo exercício de diálogo (JARES, 2008). O diálogo interrompido inviabiliza a possibilidade da convivência em geral e, em particular, a resolução de conflitos. Para o autor (2008), quando falta respeito, a convivência torna-se impossível ou, no mínimo, transforma-se em um tipo de convivência violenta e não democrática. Vê-se, assim, o quanto é importante a presença do outro para o próprio crescimento.

O convívio pacífico, tolerante e respeitoso é imprescindível em uma sociedade democrática. Assim, são necessárias a leitura e a compreensão dessa diversidade para a superação da exclusão e o convívio harmonioso com o diferente.

Para Aragão e Souza (2017, p. 144):

Além de favorecer o diálogo inter-religioso, o jeito transdisciplinar de pesquisar a realidade lança uma nova luz sobre o sentido do sagrado. Uma zona de absoluta resistência ao conhecimento liga o sujeito e o objeto, os níveis de realidade e os níveis de percepção. Mística deriva desse mistério, do respeito a esse ilimitado em todo conhecimento. Espiritualidade é religação com essa dimensão sagrada, profunda e sutil, de toda a realidade: em nosso interior, na natureza e na história, na face do outro. As tradições religiosas e filosóficas formalizam caminhos para a experiência espiritual, conforme as possibilidades e os limites de cada cultura.

A interação por meio do diálogo, em um processo dinâmico marcado pelo respeito, leva ao conhecimento produzido por diferentes tradições religiosas, pois o convívio com o diferente como fonte de aprendizagem, pelo viés da interculturalidade, possibilita o vislumbre do espaço da religião, as representações, as expressões e as percepções do discurso e do pensamento religioso. 
Todo ser humano vive e se desenvolve no interior de um conjunto muito complexo de relações, intercâmbios, colaborações e rivalidades. E os laços de linguagem, cultura, família e amizade configuram o surgimento e o desenvolvimento de cada pessoa. A partir desses laços, cada um é estimulado e limitado pelos outros seres humanos, e há uma singularidade pessoal na relação com o outro, que pensa e crê diferentemente.

Conhecer o humano é, antes de mais nada, situá-lo no universo, e não o separar dele. O pressuposto é que os estudantes têm o direito de conhecer todas as dimensões da cultura; entre estas, encontra-se a possibilidade de discutir os problemas fundamentais da existência.

Compreender o humano é compreender sua unidade na diversidade e sua diversidade na unidade. A educação deverá ilustrar esse princípio de unidade/ diversidade em todas as esferas.

A observação do contexto da sala dos estudantes em relação à diversidade cultural, respeitando suas diferenças, o investimento na atualização científica, pedagógica e cultural, estando em uma formação permanente, que é decorrente de uma perspectiva afetiva no exercício da docência, a consideração da ética na sua atuação e no deu desenvolvimento com os alunos, além da utilização das novas tecnologias da comunicação e da informação, refletem sobre seu emprego e suas possibilidades na melhoria das aulas (ROMANOWSKI, 2007).

Pensar o outro disponível para uma nova interlocução criadora, segundo Teixeira (2012), pode provocar uma ampliação de olhar e enriquecimento próprio com novas possibilidades de um processo que não acontece sem disposições prévias. Educar para conhecer o outro, que pensa, age e crê de maneira diferente é exercitar o diálogo com base no respeito profundo e no desejo de preservar a dignidade e o direito de existência de cada cultura.

\section{Considerações finais}

A educação se constitui historicamente e não acontece de forma isolada, pois está relacionada estreitamente com a sociedade e a cultura de cada época. É necessário, portanto, relacionar a educação com as concepções sociais e culturais de cada momento histórico para refletir sobre o processo de ensino e aprendizagem.

A educação para a consciência religiosa é um direito do ser humano. $\mathrm{O}$ pressuposto é que os estudantes tenham o direito de conhecer todas as dimensões da cultura, entre as quais se encontra a possibilidade de discutir os problemas fundamentais da existência. É difícil chegar às opções de vida quando se pretende ignorar a religiosidade ou, então, quando se quer restringi-la a um ensino vago, inútil, por ser destituído da relação entre os modelos históricos, coerentes com a tradição e a cultura dos povos. Essa dimensão requer a compreensão de que o processo de ensino e aprendizagem é voltado para o desenvolvimento da capacidade de aprender a aprender e de ler a vida. 
Retomando as inquietações apresentadas no início do artigo: como ver o diferente e aprender com ele a conviver em harmonia? Como abordar a questão da diversidade cultural e religiosa em sala de aula? Esse é o desafio que se apresenta. Assumir uma atitude que desenvolva a articulação com outras competências (disciplinas e conhecimentos) pode integrar os estudantes em um trabalho conjunto com vistas à educação integral. Cabe, assim, à educação utilizar-se da comunicação e do diálogo para promover o encontro com o outro e o seu sagrado.

A diversidade religiosa, advinda da elaboração cultural, sempre esteve presente na história da humanidade como uma forma de questionar o sentido da vida e do sagrado. Assim, o "letramento religioso" permite uma leitura que vai além da superfície das coisas, dos acontecimentos, dos gestos, dos ritos, das normas e das formulações, para a compreensão da realidade de maneira profunda. Sendo assim, não só o conhecimento religioso se torna objeto de compreensão, mas também o ser humano que busca tal conhecimento como resposta e sentido da vida.

$\mathrm{Na}$ relação entre competências e conhecimentos elencados na BNCC, há que se considerar que a constituição da maioria das competências objetivadas na Educação Básica atravessa as tradicionais fronteiras disciplinares e exige um trabalho integrado entre professores das diferentes disciplinas ou áreas afins.

Os professores que atuam no campo do Ensino Religioso já se encontram no meio de duas grandes áreas: a das Ciências da Religião/Teologia e a das Ciências da Educação. Ocupam-se em discutir e estudar a questão do desenvolvimento do fenômeno religioso e do conhecimento religioso, ao mesmo tempo que lecionam, para crianças e adolescentes, os conhecimentos no campo da sociologia, psicologia, antropologia e outras ciências que analisam o movimento religioso em suas diferentes facetas. As diversas áreas do conhecimento podem dar aos estudantes a "leitura" do contexto em que tais tensões se desenvolvem.

O fazer pedagógico não se revela apenas nas intenções definidas em ementas ou currículos, mas particularmente no cotidiano escolar/universitário e na formação de novos educadores para congregar os discursos científico, político, estético e religioso no mesmo campo cognitivo.

O processo de ensino e aprendizagem voltado para o desenvolvimento da capacidade de aprender a aprender e de ler a vida pode incentivar o diálogo, em um processo dinâmico marcado pelo respeito, que leva ao conhecimento produzido pelas diferentes culturas e religiões.

O espaço escolar como local da aprendizagem pode trabalhar as regras do espaço público democrático, buscando a superação de todo e qualquer tipo de discriminação e exclusão social, valorizando cada indivíduo e todos os grupos que compõem a sociedade brasileira, garantindo o exercício da cidadania, o direito da expressão religiosa e o diálogo intercultural e inter-religioso. Dessa maneira, uma abordagem pedagógica do Ensino Religioso exige o entendimento e a reflexão do espaço escolar diante do reconhecimento da justiça e dos direitos de 
igualdades civil, social, cultural e econômico, bem como a valorização da diversidade daquilo que distingue os diferentes componentes culturais de elaboração histórico-cultural da nação brasileira.

Educar para a diversidade cultural e religiosa é compreender as culturas e as religiões que lhes dão forma. É a possibilidade de analisar a relação entre presente e passado para produzir um saber histórico. É o exercício do diálogo com o diferente, com base no respeito profundo e no desejo de preservar a dignidade e o direito de existência de cada manifestação cultural-religiosa. E, nesse sentido, alguns aspectos importantes precisam ser considerados:

- o contexto social dos educandos (seus conhecimentos prévios - bagagem cultural e religiosa);

- o papel das tradições religiosas na estruturação e na manutenção das diferentes culturas e manifestações socioculturais;

- a complexidade dos assuntos religiosos em função da diversidade cultural e religiosa.

O estudante pode participar ativamente da construção do processo da aquisição de seus conhecimentos, utilizando a dimensão racional de seu ser e as dimensões sensíveis, emocionais e intuitivas. É cidadão de um mundo complexo, onde se inscrevem relações em rede, não menos complexas. Porém, ele é um ser dotado de capacidades criativas e talentosas, autônomo em seu processo de aprender.

Os conhecimentos produzidos pelas etnias, culturas e religiões podem proporcionar ao estudante oportunidades de aprendizagem que compreendam os movimentos específicos das diversas culturas, cujo substantivo religioso colabora para a formação do cidadão/estudante consciente da diversidade cultural e religiosa.

Recebido em: 06/04/2019

Revisado pelo autor em: 21/05/2019 Aceito para publicação em: 30/05/2019

\section{Notas}

1 Doutora em Teologia. Mestre em Educação pela Pontifícia Universidade Católica do Paraná (PUC-PR). Pesquisadora do Grupo Pesquisa Educação e Religião (GPER). E-mail: edile.fracaro@grupomarista.org.br

\section{Referências}

ARAGÃO, Gilbraz de Souza; SOUZA, Josilene Silva da. Objeto de estudo, objetivos e eixos do ensino religioso na base nacional comum curricular. In: JUNQUEIRA, Sérgio; BRANDENBURG, Laude; KLEIN, Remi (org.). Compêndio do ensino religioso. São Leopoldo: Sinodal; Petrópolis: Vozes, 2017. p. 143-144. 
BENEDICT, Ruth. Padrões de cultura. Petrópolis: Vozes, 2013.

BENKÖ, Antonius. Psicologia da religião. São Paulo: Edições Loyola, 1981.

BONAFÉ, Jaume Martínez. Na escola, o futuro já não é passado, ou é. Novos currículos, novos materiais. In: JARAUTA, Beatriz; IMBERNÓN, Francisco (org.). Pensando no futuro da educação: uma nova escola para o século XXI. Porto Alegre: Penso, 2015. p. 102-111.

BRASIL. Lei no 9.394, de 20 de dezembro de 1996. Estabelece as diretrizes e bases da educação nacional. Diário Oficial [da] União, Brasília, DF, 23 dez. 1996. Disponível em: http://www.planalto.gov.br/ccivil_03/leis/19394.htm. Acesso em: 18 mar. 2019.

. Base nacional comum curricular. Brasília: MEC, 2017. http://basenacionalcomum.mec.gov.br/images/BNCC_EI_EF_110518_versaofinal_site. pdf. Acesso em: 18 mar. 2019.

CAETANO, Maria Cristina. O ensino religioso e a formação de seus professores: dificuldades e perspectivas. 2007. Dissertação (Mestrado em Educação) - Pontifícia Universidade Católica de Minas Gerais, Belo Horizonte, 2007.

COSTELLA, Domenico. O fundamento epistemológico do ensino religioso. In: JUNQUEIRA, Sergio; WAGNER, Raul (org.). O ensino religioso no Brasil. Curitiba: Champagnat, 2004.

FREIRE, Paulo; FAUNDEZ, Antonio. Por uma pedagogia da pergunta. Rio de Janeiro: Paz e Terra, 1985.

GIL FILHO, Sylvio Fausto. Espaço sagrado no Islã Shi'i: notas para uma geografia da religião do Shi'ismo Duodécimano. In: SERPA, Angela (org.).

Espaços culturais: vivências, imaginações e representações [online]. Salvador: EDUFBA, 2008. p. 139-159. Disponível em: http://books.scielo.org/id/bk/ pdf/serpa-9788523211899-08.pdf. Acesso em: 18 mar. 2019.

JARES, Xesús. Pedagogia da convivência. São Paulo: Palas Athena, 2008.

JUNQUEIRA, Sérgio et al. Socialização do saber e produção científica do ensino religioso. Porto Alegre: Editora Fi, 2017.

KLUCK, Cláudia Regina. Livro didático e ensino religioso. In: JUNQUEIRA, Sérgio; BRANDENBURG, Laude; KLEIN, Remi (org.). Compêndio do ensino religioso. São Leopoldo: Sinodal; Petrópolis: Vozes, 2017. p. 260-267.

LÉVY, Pierre. Cibercultura. São Paulo: Editora 34, 1999.

MORIN, Edgar. Os sete saberes necessários à educação do futuro. São Paulo: Cortez, 2000. 
NOLETO, Marlova. A construção da cultura de paz: dez anos de história. In: UNESCO; ASSOCIAÇÃO PALAS ATHENA. Cultura de paz: da reflexão à ação; balanço da década internacional da promoção da cultura de paz e não violência em benefício das crianças do mundo. Brasília: UNESCO; São Paulo: Associação Palas Athena, 2010. p. 11-36.

PASSOS, João Décio. Teologia e outros saberes: uma introdução ao pensamento teológico. São Paulo: Paulinas, 2011.

RODRIGUES, Edile Maria Fracaro. Desenvolvimento religioso. In: JUNQUEIRA, Sérgio; BRANDENBURG, Laude; KLEIN, Remi (org.). Compêndio do ensino religioso. São Leopoldo: Sinodal; Petrópolis: Vozes, 2017. p. 207-2015.

RODRIGUES, Edile Maria Fracaro; JUNQUEIRA, Sérgio Rogério Azevedo; MARTINS FILHO, Lourival José. Perspectivas pedagógicas do ensino religioso: formação inicial para um profissional do ensino religioso. Florianópolis: Insular, 2015.

ROMANOWSKI, Joana. Formação e profissionalização docente. Curitiba: IBPEX, 2007.

SACRISTÁN, José Gimeno. Apresentação: por que nos importamos com a educação do futuro? In: JARAUTA, Beatriz; IMBERMÓN, Francisco (org.). Pensando no futuro da educação: uma nova escola para o século XXI. Tradução de Juliana dos Santos Padilha. Porto Alegre: Penso, 2015.

SENRA, Flávio. Apresentação. In: JUNQUEIRA, Sérgio Rogério Azevedo et al. Socialização do saber e produção científica do ensino religioso. Porto Alegre: Editora Fi, 2017.

SÉRVIO, Pablo Petit Passos. O que estudam os estudos de cultura visual? Revista Digital do LAV, Santa Maria, v. 7, n. 2, p. 196-215, maio/ago. 2014. Disponível em: https://periodicos.ufsm.br/revislav/article/download/12393/ pdf. Acesso em: 18 mar. 2019.

TARDIF, Maurice. Saberes docentes e formação profissional. Petrópolis: Vozes, 2002.

TEIXEIRA, Faustino. O imprescindível desafio da diferença religiosa. Revista Interdisciplinar da Mobilidade Humana, Brasília, ano XX, n. 38, p. 181194, jan./jun. 2012. Disponível em: http://www.scielo.br/pdf/remhu/v20n38/ a11v20n38.pdf. Acesso em: 18 mar. 2019.

TRENTI, Zelindo. L’esperienza religiosa. Leumann: EllediCi, 1999.

UNESCO; ASSOCIAÇÃO PALAS ATHENA. Cultura de paz: da reflexão à ação; balanço da década internacional da promoção da cultura de paz e não violência em benefício das crianças do mundo. Brasília: UNESCO; São Paulo: Associação Palas Athena, 2010. 